\title{
Anesthetic management of penetrating neck injury patient with embedded knife
} -A case report-

\author{
Hyub Huh ${ }^{2}$, Jin Hee Han², Jun-Young Chung ${ }^{2}$, Jae-Woo Yi ${ }^{2}$, Bong Jae Lee ${ }^{2}$, Dong Ok Kim², and \\ Keon-Sik Kim ${ }^{1}$
}

Department of Anesthesiology and Pain Medicine, ${ }^{1}$ Kyung Hee University Medical Center, ${ }^{2}$ Kyung Hee University Hospital at Gangdong, Seoul, Korea

Penetrating neck injuries can be a fatal event and they are difficult to manage for both surgeons and anesthesiologists. So, adequate preoperative evaluation is important to improve the patients' outcomes, but this can not be done for hemodynamically unstable or uncooperative patient. Here we present our clinical experience with a patient with a penetrating neck injury and who was hemodynamically stable, but she was uncooperative and the knife was still embedded in her neck. The surgical exploration and bronchoscopic examination were successfully done under monitored anesthesia care. (Korean J Anesthesiol 2012; 62: 172-174)

Key Words: Fiberoptic bronchoscopy, Monitored anesthesia care, Penetrating neck injury, Tracheal injury.

Penetrating neck injuries (PNI) can be a life threatening event and they usually require emergency surgical treatment. Due to the anatomical complexity of the neck region, managing these patients is very difficult and dangerous for both surgeons and anesthesiologists. Though there are reported differences, the mortality rates from such injuries have ranged from $3 \%$ to $6 \%$ due to injuries of the major vessels [1]. So, adequate preoperative evaluation like fiberoptic bronchoscopy, ultrasonography (US), computed tomography (CT) and angiography is important to confirm the extent of injuries and plan the treatment. Yet these modalities can be used in only stable and cooperative patients.
We report on an unusual case of a PNI by a knife and the knife was still stuck in the neck and the patient was uncooperative. The patient underwent surgical exploration and bronchoscopic examination before removing the knife under monitored anesthesia care (MAC).

\section{Case Report}

A 38-year-old women (height: $158.6 \mathrm{~cm}$, body weight: $61.9 \mathrm{~kg}$ ) visited our emergency department with a knife stuck in her neck due to attempted suicide. She has a history of schizophrenia and major depression for the previous 10 years

Received: April 26, 2011. Revised: 1st, June 9, 2011; 2nd, June 26, 2011. Accepted: July 4, 2011.

Corresponding author: Jun-Young Chung, M.D., Department of Anesthesiology and Pain Medicine, Kyung Hee University Hospital at Gangdong, 149, Sangil-dong, Gangdong-gu, Seoul 134-727, Korea. Tel: 82-2-440-6191, Fax: 82-2-440-7808, E-mail: madsleep@naver.com

(c) This is an open-access article distributed under the terms of the Creative Commons Attribution Non-Commercial License (http:// creativecommons.org/licenses/by-nc/3.0/), which permits unrestricted non-commercial use, distribution, and reproduction in any medium, provided the original work is properly cited. 
and the symptoms had waxed and waned. But she had stopped her anti-depressive medication about 2 months previously.

On the primary survey, the patient was alert and hemodynamically stable, but she had intermittent cough with blood tingled sputum. Though the knife was still embedded on her neck, there was no active bleeding.

We planned to perform cervical CT and fiberoptic bronchoscopic examination for evaluating the trachea, esophagus and vessels, but we could do only chest and cervical X-ray because the patient didn't cooperate. Midazolam $5 \mathrm{mg}$ was administered for sedation, but there was no effect. On the cervical X-ray, the knife was bedded on the $6^{\text {th }}$ cervical vertebra body (Fig. 1). We could not administer more sedation and perform tracheal intubation because there was possibility of tracheal laceration and intubation could worsen this. So, we decided to explore the neck and trachea under MAC and we transferred the patient to the operating room.

At the operating room, the patient was not irritable, but she was still uncooperative. At the time of admission, an electrocardiograph, a noninvasive blood pressure device and a pulse oxymeter were applied. We failed to monitor the bispectral index (BIS ${ }^{\circledR}$, Aspect Medical System, Norwood, MA, USA) because the patient was very uncooperative to attach the BIS sensor. Her initial blood pressure, heart rate and oxygen saturation were $120 / 66 \mathrm{mmHg}, 88 \mathrm{rate} / \mathrm{min}$ and $98 \%$, respectively. Glycopyrrolate $0.2 \mathrm{mg}$ was administered for premedication, and oxygen was supplied through the nasal cannula (2 L/min) which was attached in the emergency department. After that, we started to infuse remifentanil and propofol using a target-controlled infusion pump (Orchestra ${ }^{\circledR}$, Fresenius Vial, Brezins, France). Remifentanil was started at an

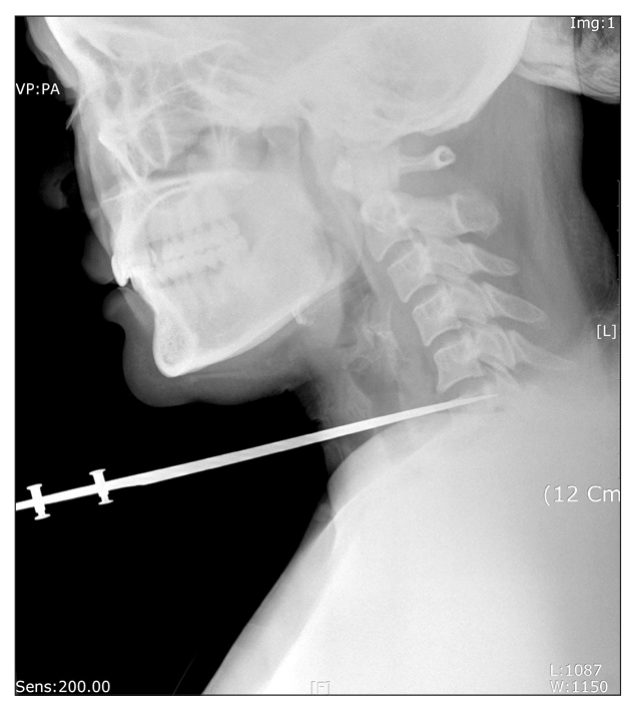

Fig. 1. The Preoperative cervical X-ray finding. The knife penetrated neck and embedded in body of 6th cervical spine. effect site concentration of $1 \mathrm{ng} / \mathrm{ml}$ (Minto's pharmacokinetic model). About 5 minute later, propofol was started at an effect site concentration of $1 \mu \mathrm{g} / \mathrm{ml}$ with careful observation of the respiration and oxygen saturation. Then a capnograph was applied for checking the respiration. We also prepared a tracheostomy set and a percutaneous cardiopulmonary support system in case of failure to secure the airway. We gradually increased the effect site concentration of propofol up to $1.5 \mu \mathrm{g} / \mathrm{ml}$. About 10 minutes after starting propofol, the patient lost consciousness. Then the BIS sensor was attached on her forehead and the value was checked as $72-75$. A $20 \mathrm{G}$ catheter was placed in the right radial artery for continuous blood pressure monitoring and arterial blood gas analysis, and a central venous catheter was placed on her right femoral vein against the active bleeding after removal of the knife.

The surgery was started after $1 \%$ lidocaine infiltration over the skin and subcutaneous tissue for local anesthesia. There was no damage to the trachea, carotid arteries and jugular veins on the surgical findings, but partial laceration of the esophagus and thyroid injury were detected. We inserted a fiberoptic bronchoscope into the reinforced endotracheal tube (I.D. 7.0 $\mathrm{mm}$ ) to prepare for bronchoscopic intubation. After that, we tried to perform a fiberoptic bronchoscopic examination after applying $4 \%$ lidocaine to the throat, vocal cords and bronchus. Fortunately, there was no visible tracheal injury on the bronchosopic examination. Next, the pre-attached endotracheal tube was pushed into the trachea. Then general anesthesia was started with increasing the effect site concentrations of propofol and remifentanil up to $2.5 \mu \mathrm{g} / \mathrm{ml}$ and $2.0 \mathrm{ng} / \mathrm{ml}$ each, and we administered rocuronium $50 \mathrm{mg}$.

The knife was removed by the surgeon with careful observation of the vessels, thyroid gland and trachea. Primary repair of the damaged esophagus and bleeding control were done.

At the end of surgery, the patient was awakened and the endotracheal tube was removed with good self respiration. She was transferred to the intensive care unit for close observation. Two weeks after operation, there was no complication and the patient was transferred to a mental hospital to treat her psychiatric problems.

\section{Discussion}

There are many important vital structures in the neck region, and they can be easily damaged due to their proximity to the skin. Neck injuries can be a life threatening event due to bleeding from the great vessels, airway obstruction from tracheal injury or hematoma, esophageal injury and other neural damage. Appropriate, rapid management is critical in order to improve the outcomes.

The anatomical region of the neck can be divided into three 
zones for the purpose of evaluating and treating penetrating injuries [2]. Zone I extends from the clavicles to the cricoid cartilage, zone II extends from the inferior margin of the cricoid cartilage to the angle of the mandible and zone III is located from the angle of the mandible to the base of the skull. If the patient has hard signs of significant injury like active hemorrhage, expanding hematoma, bruit, pulse deficit, subcutaneous emphysema, hoarsness, stridor, respiratory distress or hemiparesis, immediate surgical management is indicated [3]. But in hemodynamically stable patients, preoperative US, CT and angiography are very useful for determining the extent of injuries. Especially in zone I injury, angiography and esophagography should be done before operation because the surgical approach is difficult and vascular and esophageal injuries are frequently combined in zone I [4].

However, through attention should be paid to the patient's airway during the evaluation period, and the airway should definitely be controlled with endotracheal intubation [5]. But if the patient has tracheal injury, conventional endotracheal intubation with direct laryngoscopy can aggravate the injury and this may even lead to complete disruption of the trachea [6]. There are some clinical signs that suggest tracheal injury and these are hoarsness, subcutaneous emphysema, dyspnea, dysphagia and hemoptysis [7]. So, fiberoptic bronchoscopic examination and intubation can be very helpful.

Awake fiberoptic intubation is the safest method for most patients and it should be considered for all cooperative patients with suspected airway injury [8].

In our case, the patient had zone I PNI and she was in a hemodynamically stable state. So, CT angiography, esophagogram and fiberoptic bronchoscopic examination were necessary, but the patient was not cooperative because she was suffering from schizophrenia and major depression and the knife was still embedded on her neck. Embedded foreign bodies such as the knife must never be removed from the neck until the patient is sedated in the operating room because the removal of the knife can cause bleeding from deep structures and this is difficult to control unless immediate surgical exploration can be performed [5].

In case of suspected tracheal injury, keeping self respiration is favorable because positive pressure ventilation before intubation can aggravate tracheal injury and cause subcutaneous emphysema [9].

In our case, preoperative evaluation and awake fiberoptic bronchoscopy were deemed most appropriate, but we could not perform these due to the uncooperative patient. We were able to adequately sedate the patient by an infusion of remifentanil and propofol, and surgical exploration and bronchoscopic examination were then successfully done.

If a patient with penetrating neck trauma can not be evaluated and awake intubation using fiberoptic bronchoscopy is difficult or impossible, then MAC can be another alternative.

\section{References}

1. Brywczynski JJ, Barrett TW, Lyon JA, Cotton BA. Management of penetrating neck injury in the emergency department: a structured literature review. Emerg Med J 2008; 25: 711-5.

2. Roon AJ, Christensen N. Evaluation and treatment of penetrating cervical injuries. J Trauma 1979; 19: 391-7.

3. Tisherman SA, Bokhari F, Collier B, Cumming J, Ebert J, Holevar M, et al. Clinical practice guideline: penetrating zone II neck trauma. J Trauma 2008; 64: 1392-405.

4. Biffl WL, Moore EE, Rehse DH, Offner PJ, Franciose RJ, Burch JM. Selective management of penetrating neck trauma based on cervical level of injury. Am J Surg 1997; 174: 678-82.

5. Ursic C, Curtis K. Thoracic and neck trauma. Part four. Int Emerg Nurs 2010; 18: 177-80

6. Kelly JP, Webb WR, Moulder PV, Everson C, Burch BH, Lindsey ES. Management of airway trauma. I: Tracheobronchial injuries. Ann Thorac Surg 1985; 40: 551-5.

7. Bhattacharya P, Mandal MC, Das S, Mukhopadhyay S, Basu SR. Airway management of two patients with penetrating neck trauma. Indian J Anaesth 2009; 53: 348-51.

8. Desjardins G, Varon AJ. Airway management for penetrating neck injuries: the Miami experience. Resuscitation 2001; 48: 71-5.

9. Lee KH, Park CH, Ahn YM. Anesthetic review of complete tracheal transection by blunt trauma. Korean J Anesthesiol 1998; 35: 1174-9. 